Vietnam Journal of Mechanics, VAST, Vol.33, No. 2 (2011), pp. $105-112$

\title{
EXPERIMENTAL STUDY ON MECHANICAL PROPERTIES FOR A THREE - PHASE POLYMER COMPOSITE REINFORCED BY GLASS FIBERS AND TITANIUM OXIDE PARTICLES
}

\author{
Nguyen Dinh Duc ${ }^{1}$, Dinh Khac Minh ${ }^{2}$ \\ ${ }^{1}$ University of Engineering and Technology \\ ${ }^{2}$ Shipbuilding Science and Technology Institute
}

\begin{abstract}
Nowadays, composite materials are applied in many fields. The physico mechanical properties of the material can be improved by adding reinforced fibers and particles. Many scientists pay attention to the calculation for elastic modules of three phase composite materials. This report presents the experimental results for some elastic modules of three - phase polymer composite reinforced with glass fibers and titanium oxide particles of different volume ratios. A comparison between experimental and theoretical results shows good agreement.
\end{abstract}

Key words: Three - phase composite (polyester, glass fiber, titanium oxide), elastic modulus, experimental.

\section{INTRODUCTION}

Composite material consists of two or more component materials to obtain a new material with better properties. The components are matrix material and filled materials (reinforced or additive). The function of matrix material is to unite the components, assure the resistance to heat and physicochemical loads, while the filled components are used to improve the mechanical properties (stiffness and strength) of the composite $[5,6,7,10]$.

The reinforced components used usually are fibers and particles. Fibers can increase the stiffness, while particles can decrease the fracture, plastic strain and improve the water and gas proof ability of the composite. Thus, the addition of fibers and particles can make composite become more perfect, to satisfy more and more requirements of modern technology.

Having advantages such as: light weight, resistance to heat and environmental loads, composite materials are widely applied in many fields: from industry, construction, machine - building, transportation to aerospace engineering and medical engineering. In Vietnam, within the past ten years, many researches and applications for composite have been done, especially for polymer composites. The properties of polymer composites is indicated in $[5,6,9]$. In ship building industry, guard ship, passenger ship, fishing vessel of small and medium sizes are mainly made of composite materials. To improve the water - proof, fire 
- proof, corrosion - proof and crack resistant properties of the material, particles often be added to the matrix besides fibers. This leads to the appearance of three - phase composite which having three phases: polymer matrix, reinforced fibers and particles. To deal with the structural problems, we need to know the mechanical behavior of the material, which means firstly determining the elastic modules of the composite (Fig. 1).

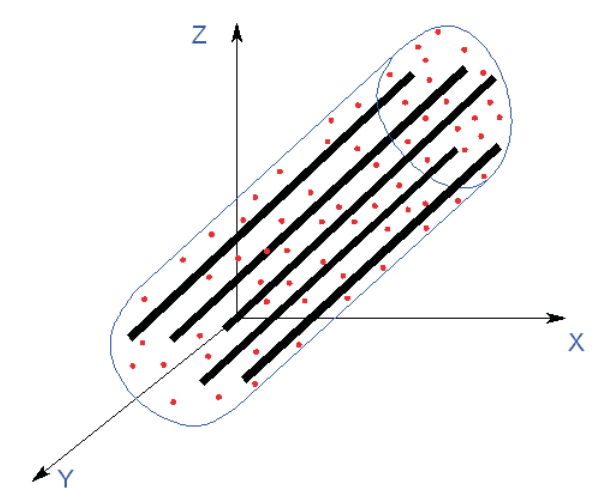

Fig. 1. Model of three - phase composite with reinforced fiber and particle

\section{DETERMINE THE ELASTIC MODULES OF THREE - PHASE COMPOSITE}

There are two main methods for determining the elastic modules of three - phase composite material: experimental and analytical methods. The advantage of experimental method is that it can provide the exact result for the material's modules. However, since three - phase composite is a multi - component material, the experiment can not illustrate the effect that the component phases have on the overall mechanical properties of the material. The analytical method often uses a mechanical model of a three-phase composite material reinforced with fibers (normally in cylindrical shape) and particles (in spherical shape) to calculate the material's elastic modules. It has a principal advantage: the modules are explicitly determined from the properties and aspect ratios of the component phase. When these factors are changed, new composite is obtained and their physicomechanical properties can be predicted, thus this method provides the foundation for optimal design of new material and structure.

Another method is the inductive method, in which the predicted formulas for the elastic modules are derived based on a large number of experiments. Such formulas are often suggested by the scientists in experimental physics. But with the appearance of the third phase, the experiments and the prediction for the variation of the elastic modules from the component phases' parameters become very complex. So far we have only seen publications [10] using this method for two - phase composites (matrix and reinforced particles).

In our previous reports, the elastic modules of three - phase composites are estimated using two theoretical models of the two - phase composite consecutively: $\mathrm{nD}_{m}=\mathrm{O}_{m}+\mathrm{nD}$ 
$[3,4,12]$. This paper considers three - phase composite reinforced with particles and unidirectional fibers, so the problem's model will be: $1 \mathrm{D}_{m}=\mathrm{O}_{m}+1 \mathrm{D}$.

The researches on determining the elastic modules for composite material with reinforced particles are reported in $[1,2,10,11,12]$. In our papers $[11,12]$, the interaction between matrix and particles is taken into account. Firstly, the modules of the effective matrix $\mathrm{O}_{m}$ which called "effective modules" are calculated. In this step, the effective matrix consists of the original matrix and particles, it is considered to be homogeneous, isotropic and have two elastic modules. The next step is estimating the elastic modules for a composite material consists of the effective matrix and unidirectional reinforced fibers.

Thus, the result for the three - phase composite problem depends much on the models for the two - phase composite problem and it can have different accuracy for different composites.

For composite reinforced with particles, several methods for determining elastic modules have been proposed $[1,2,10,11,12]$. In this research, we chose the method which takes into account the interaction between matrix and particle $[2,12]$.

There are also researches on determining the elastic modules for composite reinforced by unidirectional fibers $[1,7,8,11]$. This type of material is often considered orthotropic with 5 elastic modules $[1,7]$. The most modern reports with two independent approaches by Pobedrya B.E. [8] and Vanin G.A. [11] have calculated the sixth modulus of this material, and their results show good agreement to each other.

Assume that all the component phases (matrix, fiber and particle) are homogeneous and isotropic, we will use $\mathrm{E}_{m}, \nu_{m}, \mathrm{E}_{a}, \nu_{a}, \mathrm{E}_{c}, \nu_{c}$ to denote Young modulus and Poisson ratio for matrix, fiber and particle, respectively. According to [2], we can obtain the modules for the effective composite as below:

$$
\begin{gathered}
\bar{G}=G_{m} \frac{1-\xi_{c}\left(7-5 \nu_{m}\right) H}{1+\xi_{c}\left(8-10 \nu_{m}\right) H} \\
\bar{K}=K_{m} \frac{1+4 \xi_{c} G_{m} L\left(3 K_{m}\right)^{-1}}{1-4 \xi_{c} G_{m} L\left(3 K_{m}\right)^{-1}}
\end{gathered}
$$

here,

$$
L=\frac{K_{c}-K_{m}}{K_{c}+\frac{4 G_{m}}{3}}, \quad H=\frac{G_{m} / G_{c}-1}{8-10 \nu_{m}+\left(7-5 \nu_{m}\right) \frac{G_{m}}{G_{c}}} .
$$

$\bar{E}, \bar{\nu}$ can be calculate from $(\bar{G}, \bar{K})$ as below

$$
\bar{E}=\frac{9 \bar{K} \bar{G}}{3 \bar{K}+\bar{G}}, \quad \bar{\nu}=\frac{3 \bar{K}-2 \bar{G}}{6 \bar{K}-2 \bar{G}}
$$

The modules for three - phase composite reinforced with unidirectional fiber are chosen to be calculated using Vanin's formulas [11]: 


$$
\begin{aligned}
& E_{11}=\xi_{a} E_{a}+\left(1-\xi_{a}\right) \bar{E}+\frac{8 \bar{G} \xi_{a}\left(1-\xi_{a}\right)\left(\nu_{a}-\bar{\nu}\right)}{2-\xi_{a}+\bar{x} \xi_{a}+\left(1-\xi_{a}\right)\left(x_{a}-1\right) \frac{\bar{G}}{G_{a}}}, \\
& E_{22}=\left\{\frac{\nu_{21}^{2}}{E_{11}}+\frac{1}{8 \bar{G}}\left[\frac{2\left(1-\xi_{a}\right)(\bar{\chi}-1)+\left(\chi_{a}-1\right)\left(\bar{\chi}-1+2 \xi_{a}\right) \frac{\bar{G}}{G_{a}}}{2-\xi_{a}+\bar{\chi} \xi_{a}+\left(1-\xi_{a}\right)\left(\chi_{a}-1\right) \frac{\bar{G}}{G_{a}}}+\right.\right. \\
& \left.\left.+2 \frac{\bar{\chi}\left(1-\xi_{a}\right)+\left(1+\xi_{a} \bar{\chi}\right) \frac{\bar{G}}{G_{a}}}{\bar{\chi}+\xi_{a}+\left(1-\xi_{a}\right) \frac{\bar{G}}{G_{a}}}\right]\right\}^{-1} \\
& G_{12}=\bar{G} \frac{1+\xi_{a}+\left(1-\xi_{a}\right) \frac{\bar{G}}{G_{a}}}{1-\xi_{a}+\left(1+\xi_{a}\right) \frac{\bar{G}}{G_{a}}}, \quad G_{23}=\bar{G} \frac{\bar{\chi}+\xi_{a}+\left(1-\xi_{a}\right) \frac{\bar{G}}{G_{a}}}{\left(1-\xi_{a}\right) \bar{\chi}+\left(1+\bar{\chi} \xi_{a}\right) \frac{\bar{G}}{G_{a}}} \\
& \frac{\nu_{23}}{E_{22}}=-\frac{\nu_{21}^{2}}{E_{11}}+\frac{1}{8 \bar{G}}\left[2 \frac{\left(1-\xi_{a}\right) \bar{x}+\left(1+\xi_{a} \bar{x}\right) \frac{\bar{G}}{G_{a}}}{\bar{x}+\xi_{a}+\left(1-\xi_{a}\right) \frac{\bar{G}}{G_{a}}}-\right. \\
& \left.-\frac{2\left(1-\xi_{a}\right)(\bar{x}-1)+\left(x_{a}-1\right)\left(\bar{x}-1+2 \xi_{a}\right) \frac{\bar{G}}{G_{a}}}{2-\xi_{a}+\bar{x} \xi_{a}+\left(1-\xi_{a}\right)\left(x_{a}-1\right) \frac{\bar{G}}{G_{a}}}\right], \\
& \nu_{21}=\bar{\nu}-\frac{(\bar{\chi}+1)\left(\bar{\nu}-\nu_{a}\right) \xi_{a}}{2-\xi_{a}+\bar{\chi} \xi_{a}+\left(1-\xi_{a}\right)\left(\chi_{a}-1\right) \frac{\bar{G}}{G_{a}}} .
\end{aligned}
$$

in which $\bar{x}=3-4 \bar{\nu}$.

One of the goals of this research is to do the experiments to verify the results for the modules $\mathrm{E}_{11}, \mathrm{E}_{22}, \mathrm{G}_{12}$ of three - phase composite materials calculated using the formulas (5) above.

\section{EXPERIMENT AND RESULT}

To verify Young modules for three - phase composite, we tested the samples made of polyester AKAVINA (made in Vietnam), fibers (made in Korea) and titanium oxide (made in Australia) with the properties as in Table 1.

The experiments were done on HOUNSFEILD H50K-S tester (Fig. 2) using BS EN ISO 527-1: 1997 method. Room's temperature was $\left(20 \pm 5^{0} \mathrm{C}\right)$, humidity was $65 \% \pm 20 \%$. The samples were made according to Vietnamese standard code: TCVN 6282:2008 [13]. The dimension of the samples is given in Fig. 3. The experiments were done at the Laboratory of Shipbuilding Technology Institute, Nha Trang University. 
Table 1. Properties of component phases for the three - phase composite

\begin{tabular}{|c|c|c|}
\hline Component phase & Young modulus E & Poisson ratio $\nu$ \\
\hline Matrix polyester AKAVINA (Vietnam) & $1,43 \mathrm{Gpa}$ & 0.345 \\
\hline Glass fiber (Korea) & $22 \mathrm{Gpa}$ & 0.24 \\
\hline Titanium oxide $\mathrm{TiO}_{2}$ (Australia) & $5,58 \mathrm{Gpa}$ & 0.20 \\
\hline
\end{tabular}

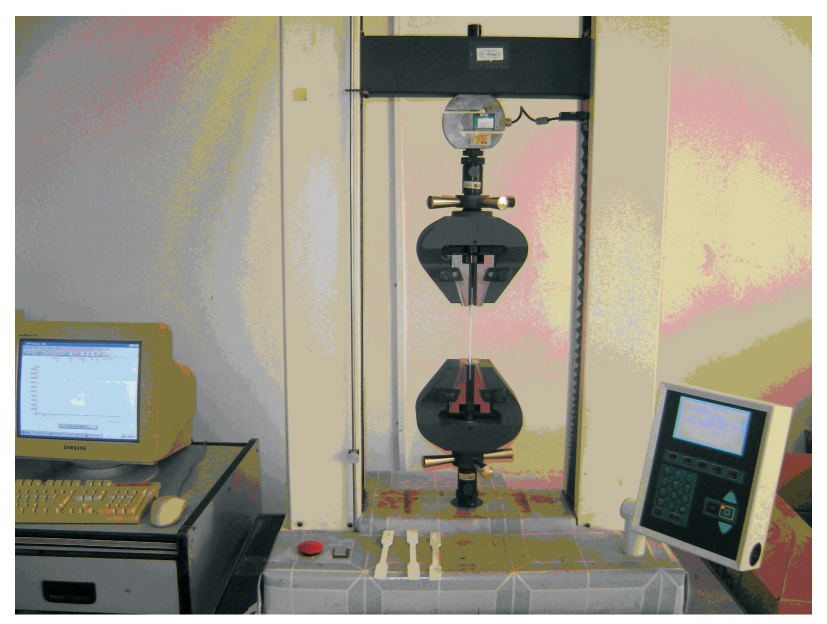

Fig. 2. HOUNSFEILD H50K-S Tester

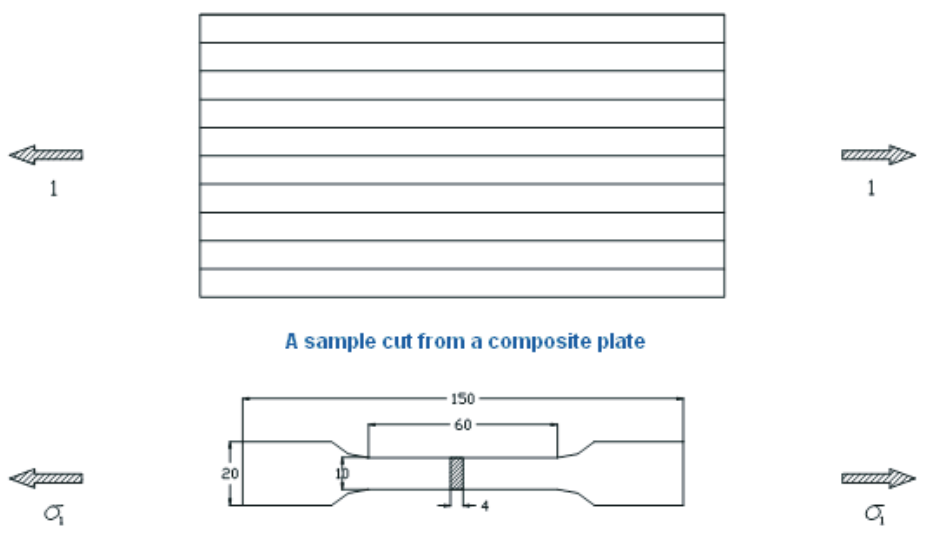

Fig. 3. Dimension of three - phase composite sample

Totally more than 60 samples were tested for 8 different cases of fibers and particle's volume ratios (as in the first column of Table 2). Tensile test was done for estimating $\mathrm{E}_{11}$, $\mathrm{E}_{22}$ and in 45 degree direction for estimating $\mathrm{E}_{45}$ and $\mathrm{G}_{12}$. The experiments' results is given in Table 2.

According to the tests' results, fiber has much effect on improving Young modulus, while particle has much effect on shear modulus. 
Table 2. Experiment results for three - phase composite's elastic modules

\begin{tabular}{|c|c|c|c|c|}
\hline & \multicolumn{4}{|c|}{ Elastic Modulus } \\
\hline Composite & $\mathbf{E}_{45}$ & $\overline{\mathbf{E}_{1}}$ & $\mathbf{E}_{2}$ & $\mathbf{G}_{12}$ \\
\hline \multirow{4}{*}{$20 \% \mathrm{TiO}_{2}+15 \% \mathrm{~W} 800+65 \%$ polyester } & 3012.36 & 4548.25 & 2750.58 & 742.07 \\
\hline & 2996 & 4673.56 & 2678.5 & 720.138 \\
\hline & 2977.7 & 4695.67 & 2670.26 & 700.504 \\
\hline & 2879.5 & 4825.34 & 2740.79 & 700.18 \\
\hline \multirow{4}{*}{$20 \% \mathrm{TiO}_{2}+20 \% \mathrm{~W} 800+60 \%$ polyester } & 3768.89 & 6208.64 & 2828.56 & 719.518 \\
\hline & 3752.2 & 6330.28 & 2931.42 & 715.799 \\
\hline & 3527.23 & 6347.5 & 2815.96 & 713.146 \\
\hline & 3340.08 & 6191.18 & 2923.98 & 712.51 \\
\hline \multirow{5}{*}{ 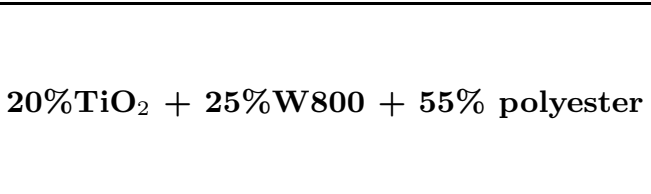 } & 3725.65 & 7270.8 & 3018.02 & 701.868 \\
\hline & 4001.73 & 6981 & 3158.63 & 702.952 \\
\hline & 3791.82 & 6959.8 & 3377.35 & 705.731 \\
\hline & 3582.3 & 6911 & 3045.76 & 701.31 \\
\hline & 3889.3 & 6956 & 3072.91 & 702.432 \\
\hline \multirow{3}{*}{$20 \% \mathrm{TiO}_{2}+30 \% \mathrm{~W} 800+50 \%$ polyester } & 4330 & 7658.5 & 3230.54 & 677.701 \\
\hline & 4275 & 7580.4 & 3267.62 & 697.542 \\
\hline & 4106.81 & 7604 & 3254.59 & 700.201 \\
\hline \multirow{4}{*}{$30 \% \mathrm{TiO}_{2}+15 \% \mathrm{~W} 800+55 \%$ polyester } & 2046.11 & 4725 & 2939.3 & 818.577 \\
\hline & 2467.39 & 4774 & 2932.81 & 800.125 \\
\hline & 2614.2 & 5073 & 3033.59 & 844.859 \\
\hline & 2244.17 & 5231 & 2997.34 & 801.6411 \\
\hline \multirow{3}{*}{$30 \% \mathrm{TiO}_{2}+20 \% \mathrm{~W} 800+50 \%$ polyester } & 4025 & 6341 & 3278.59 & 807.049 \\
\hline & 3819.55 & 6423 & 3146.34 & 801.252 \\
\hline & 3738.52 & 6582.5 & 3178.75 & 803.382 \\
\hline \multirow{4}{*}{$30 \% \mathrm{TiO}_{2}+25 \% \mathrm{~W} 800+45 \%$ polyester } & 3661.27 & 6875 & 3425.62 & 799.966 \\
\hline & 3992.65 & 6465 & 3462.25 & 805.524 \\
\hline & 3623.84 & 7012 & 3659.15 & 791.349 \\
\hline & 3707.86 & 6609 & 3547.13 & 786.753 \\
\hline \multirow{4}{*}{$30 \% \mathrm{TiO}_{2}+30 \% \mathrm{~W} 800+40 \%$ polyester } & 4342.58 & 8230 & 3655.53 & 768.72 \\
\hline & 4229.44 & 8308 & 3708.33 & 761.511 \\
\hline & 4090 & 8092 & 3602.52 & 775.503 \\
\hline & 4111.5 & 8792 & 3670.48 & 801.844 \\
\hline
\end{tabular}

The comparison between experimental results (average values from Table 2) with theoretical result ( formulas (5)) is shown in Table 3.

\section{CONCLUSION}

From Table 3, we can obtain that the theoretical analysis and experiment have good agreement for elastic modules of three - phase composite made of polyester matrix, glass fibers and titanium oxide particles. This conclusion allows us to apply the algorithm and formulas proposed in this research for estimating the elastic modules and other structure and material problems using three - phase composite.

The authors would like to thank the Laboratory of Shipbuilding Technology Institute, Nha Trang University for their assistance on experiments. 
Table 3. Comparison between experiment and analysis

\begin{tabular}{|c|c|c|c|c|}
\hline Composite & & $\mathbf{E}_{1}$ & $\overline{\mathbf{E}_{2}}$ & $\mathbf{G}_{12}$ \\
\hline \multirow{3}{*}{$20 \% \mathrm{TiO}_{2}+15 \% \mathrm{~W} 800+65 \%$ polyester } & Experimental & 4685.70 & 2709.95 & 715.72 \\
\hline & Theoretical & 4787.5 & 2791.0 & 673.8 \\
\hline & Error & $2.1 \%$ & $2.9 \%$ & $6.2 \%$ \\
\hline \multirow{3}{*}{$20 \% \mathrm{TiO}_{2}+20 \% \mathrm{~W} 800+60 \%$ polyester } & Experimental & 6269.4 & 2874.98 & 715.24 \\
\hline & Theoretical & 5781.7 & 2996.7 & 666.9 \\
\hline & Error & $8.4 \%$ & $4.1 \%$ & $7.3 \%$ \\
\hline \multirow{3}{*}{$20 \% \mathrm{TiO}_{2}+25 \% \mathrm{~W} 800+55 \%$ polyester } & Experimental & 7015.72 & 3152.55 & 708.65 \\
\hline & Theoretical & 6778.4 & 3221.7 & 659.3 \\
\hline & Error & $3.5 \%$ & $2.2 \%$ & $7.5 \%$ \\
\hline \multirow{3}{*}{$20 \% \mathrm{TiO}_{2}+30 \% \mathrm{~W} 800+50 \%$ polyester } & Experin & 7614.3 & 3250.91 & 691.8 \\
\hline & Theore & 7777.5 & 3468.9 & 650.7 \\
\hline & Errc & $2.1 \%$ & $6.7 \%$ & $6.3 \%$ \\
\hline \multirow{3}{*}{$30 \% \mathrm{TiO} 2+15 \% \mathrm{~W} 800+55 \%$ polyester } & Experimental & 4950.75 & 2975.76 & 816.30 \\
\hline & Theoretical & 4980.5 & 3091.6 & 766.5 \\
\hline & Error & $0.6 \%$ & $3.7 \%$ & $6.5 \%$ \\
\hline \multirow{3}{*}{$30 \% \mathrm{TiO}_{2}+20 \% \mathrm{~W} 800+50 \%$ polyester } & Experimental & 6348.6 & 3201.22 & 803.9 \\
\hline & Theoretical & 5962.1 & 3310.4 & 757.7 \\
\hline & Error & $6.5 \%$ & $3.4 \%$ & $6.1 \%$ \\
\hline \multirow{3}{*}{$30 \% \mathrm{TiO}_{2}+25 \% \mathrm{~W} 800+45 \%$ polyester } & Experim & 6717.75 & 3523.54 & 795.90 \\
\hline & Theoretical & 6946.3 & 3549.1 & 747.9 \\
\hline & Error & $3.4 \%$ & $0.7 \%$ & $6.4 \%$ \\
\hline \multirow{3}{*}{$30 \% \mathrm{TiO}_{2}+30 \% \mathrm{~W} 800+40 \%$ polyester } & Experimental & 8355.5 & 3659.22 & 776.89 \\
\hline & Theoretical & 7933.1 & 3810.6 & 737.0 \\
\hline & Error & $5.3 \%$ & $4.1 \%$ & $5.4 \%$ \\
\hline
\end{tabular}

The results of researching presented in the paper have been performed according to scientific research project of Vietnam National University, Hanoi (VNU, Hanoi), coded QGTĐ.09.01.

\section{REFERENCES}

[1] R. M. Christensen, Mechanics of composite materials, Joln Wiley and Sors Inc. New York, (1979).

[2] Nguyen Dinh Duc, Mechanics of nanocomposite materials, Journal of Science - Mathematic Physics, Vietnam National University, Hanoi, 19(4) (2003) 13 - 18.

[3] Nguyen Dinh Duc, Luu Van Boi, Nguyen Tien Dac, Determining thermal expansion coefficients of three - phase fibber composite material reinforced by spherical particles, Journal of Science - Mathematic - Physics, Vietnam National University, Hanoi, 24(2) (2008) 57-65.

[4] Nguyen Dinh Duc, Dinh Khac Minh, Bending analysis of three - phase polymer composite plates reinforced by glass fibres and Titanium oxide particles, Journal Computational Materials Sciences, 49(4) (2010) 194 - 198.

[5] J. A. Manson, L. H. Sperling, Polymer Blends and Composite, Plenum, New York, (1976).

[6] L. E. Nielson, Mechanics properties of Polymers and Composites, Marcel Dekker, New York, $2(1974)$.

[7] L. F. Nielsen, Composite Materials, Springer Berlin Heidelberg, New York, (2005).

[8] B. E. Pobedrya, Mechanics of composite materials, MSU, Moscow, (1984) (in Russian). 
[9] Shackelford, James F. et al, Materials Science and Engineering Handbook, CRC Press LLC, (2001).

[10] Thomas P. Selvin, Joseph Kuruvilla, Thomas Sabu, Mechanical properties of titanium dioxidefilled polystyrene micro composites, Journal Materials Letters , 58 (2004) 281 - 289.

[11] G. A. Vanin, Micro - Mechanics of composite materials, "Nauka Dumka", Kiev, (1985) (in Russian).

[12] G. A. Vanin, Nguyen Dinh Duc, The theory of spherofiberous composite.1: The input relations, hypothesis and models, Journal Mechanics of Composite Materials, 32(3) (1996) 291 - 305.

[13] Vietnamese standards code TCVN 6282:2008 for testing and manufacturing ship made of composite polyme reinforced by glass fibers, Transportation Publishing House, Hanoi, (2008).

Received September 20, 2010 